\title{
INVESTIGACIÓN CON CÉLULAS MADRES: UN PROBLEMA JURÍDICO
}

\author{
POR \\ RAFAEL RUBIO NÚÑEZ \\ Profesor de Derecho Constitucional \\ Universidad Complutense. Madrid
}




\section{SUMARIO}

1. La ciencia y los compartimentos estancos. 2. Clonación, células madre EMBRIONARIAS Y CÉLULAS MADRE ADULTAS. 3. EL BIEN JURIDICO PROTEGIDO: ¿UN ESTATUTO PARA EL EMBRIÓN? 4. EL MARCO LEGISLATIVO: LA FECUNDACIÓN IN VITRO. 5. CLONACIÓN: CREACIÓN DE EMBRIONES PARA LA INVESTIGACIÓN. 6. EMBRIONES «SOBRANTES» DE LOS PROCESOS DE FECUNDACIÓN IN VITRO. 7. LA REFORMA DE LA LEY 35/1988. 8. UTILIZACIÓN CIENTIFICA DE LOS EMBRIONES "SOBRANTES". OTRAS ALTERNATIVAS CONFORMES A LA LEGALIDAD. 


\section{INVESTIGACIÓN CON CÉLULAS MADRES: UN PROBLEMA JURÍDICO}

POR

RAFAEL RUBIO NÚÑEZ

Profesor de Derecho Constitucional

Universidad Complutense. Madrid

\section{LA CIENCIAY LOS COMPARTIMENTOS ESTANCOS.}

"La biología no conoce ninguna moral» ${ }^{1}$; esta frase tan rotunda en la que el investigador alemán Dieter E. Zimmer aboga por eludir categorias morales como la libertad y la responsabilidad, poniendonos en manos de una sola ley, la de la naturaleza, es un resumen de la postura que, frecuentemente, se adopta al hablar de la investigación con embriones, tratando de reducir el debate exclusivamente al campo científico, y denunciando cualquier aportación de otras disciplinas como intrusismo profesional, ético, moral o religioso. Desde esta postura se intenta explicar a la sociedad que materias como la investigación con células madres no son su problema, y que debe ser la ciencia la que decida la utilización o no de estas células para la investigación. Un enfrentamiento técnico, en el que debe salir triunfador aquel que sea científicamente más poderoso.

1 ZIMMER, Dieter E. DIE ZEIT, nr. 8. enero, 1998, Hamburg. 
Esa actitud, tantas veces repetida en las discusiones que han tenido lugar en nuestro país en los últimos meses no dejan de recordar aquella imagen del que contemplaba el mundo por un tubo y que iba tropezando a su paso con innumerables obstáculos que era incapaz de ver. Como resume la sabiduría popular, las ramas no dejan ver el bosque, algo que en la ciencia tiene un peligro superior al crear visiones deformes $y$ en última instancia falsas, de la realidad.

Se oyen detrás de estas voces los ecos de batallas antiguas: la contraposición de ética y ciencia, como si se tratara de disciplinas que siempre se debieran presentar separadas; la utopía modernista del progreso indefinido que no admite ningún tipo de límite para la investigación científica.... el ideal ilustrado.

Este pensamiento, bastante extendido, no es único y son bastantes los que frente a esta postura acuden a la «ilustración" en el mejor sentido de la palabra. La ilustración se dirige tanto contra los miedos irracionales y las visiones apocalípticas como contra las puras fantasías de omnipotencia tecnológica. La reflexión ética no debe degenerar en mera tapadera para decisiones adoptadas de antemano" ${ }^{2}$. Algo con lo que coincide el filósofo alemán Jürgen Habermass, "No es la naturaleza la que prohibe la clonación. Nosotros mismos tenemos que decidir, la biologia no nos puede dispensar de consideraciones morales» ${ }^{3}$, y asi aparece, cuando el debate llega hasta la clonación reproductiva, ante anuncios como el que recientemente han hecho los miembros de la secta de los raelianos, el clamor en contra es unánime; nadie duda entonces de la necesidad de poner limites a la ciencia, todos recurren a motivos éticos y uno no deja de preguntarse por qué: No hay pretensión más estupida que aquella que intenta reducir el problema de la investigación con células a la opinión de los científicos, desoyendo a filósofos, antropólogos, juristas, médicos y por qué no, teólogos. Cómo decía el Presidente de la República Alemana Johannes Rau, estamos ante cuestiones que "nos afectan a todos. Cuestiones que debe debatir la sociedad en su conjunto y que a continuación deben ser objeto de decisiones políticas en el Parlamenton 4 .

Aunque hablemos de las nuevas posibilidades que ofrecen las «ciencia de la vida», no estamos ante cuestiones científicas o técnicas. Por enci-

2 RAU, Johannes. "¿lrá todo bien? Por un progreso a escala humana". Traducción de Ernesto Calabuig, Nueva Revista 76, Julio-Agosto 2001.

3 HABERMASS, Jünger. Biologie kennt keine Moral. Nicht die Natur Verbietet das Klonen. Wir müssen selbst entscheiden, DIE ZEIT, nr. 9. febrero, 1998, Hamburg.

4 RAU, Johannes. "¿lrá todo bien? Por un progreso a escala humana». Traducción de Ernesto Calabuig, Nueva Revista 76, Julio-Agosto 2001. 
ma de todo se trata de decisiones evaluadoras. "Tenemos que saber qué imagen tenemos del ser humano y cómo queremos vivir. Formular principios éticos implica ponerse de acuerdo respecto de las medidas y los límites. Desde luego siempre es muy fácil rechazar las uvas que cuelgan, inalcanzables, en lo alto. Lo difícil es fijar y aceptar límites donde sería posible transgredirlos. Respetarlos aunque incluso haya que renunciar a determinadas ventajas. Pero creo que es justamente eso lo que tenemos que hacer.

Contra toda promesa de salvación y contra todo sentimiento de impotencia yo afirmo: el progreso a medida humana es un progreso consciente de su valor y sus valores. Lo contrario de un progreso sin límites no es ni el estancamiento ni el retroceso. Quien se opone a un progreso a cualquier precio no es un enemigo del progreso" ${ }^{5}$.

\section{CLONACIÓN, CÉLULAS MADRE EMBRIONARIAS Y CÉLULAS MADRES ADULTAS.}

En los últimos años se han producido avances espectaculares en la investigación con células que han empezado a dar sus primeros resultados y que auguran un futuro prometedor a la medicina regenerativa. Estos avances se basan principalmente en el descubrimiento del potencial de las células madre que son aquellas que pueden transformarse en cualquiera de las 200 variedades celulares que integran nuestros órganos y tejidos. Estas células se pueden obtener principalmente en embriones, pero también se encuentran en la edad adulta en lugares como la médula osea o el cordón umbilical presentando cada una de ellas características diversas.

\section{a) Células madres embrionarias}

Hoy nadie duda que el arranque de la vida humana se encuentra en el cigoto, resultado de la unión del espermatozoide y el óvulo, en su interior se encuentra toda la información necesaria para llegar a desarrollarse como un cuerpo entero, de hombre o mujer ${ }^{6}$. Las células que forman el cigoto, a través de divisiones sucesivas que terminan por producir todo

${ }^{5}$ Rau, Johannes. «¿lrá todo bien? Por un progreso a escala humana». Traducción de Ernesto Calabuig, Nueva Revista 76, Julio-Agosto 2001.

6 Nature, "Su destino desde el día uno", sobre las investigaciones de Richard Gardner y Magdalena Zernicka-Goetz. Citado por Esteban Santiago, «Suposiciones y realidades", Nueva Revista, noviembre-diciembre, 2002. 
tipo de células, terminarán formando el organismo adulto, de ahí su totipotencialidad, y su enorme interés científico. "Si nada se interpone en su camino, este mensaje irá, paso a paso, produciendo una biología que es ya, desde ese instante, fuente también de una biografian?.

Al cabo de seis o siete días el embrión se configura como blastocisto $y$ entre ese momento y hasta los catorce días tiene lugar su anidación en el útero. Las células de la masa interna del blastocisto se organizarán en esta fase como disco embrionario bilaminar que en la siguiente fase se transformará en trilaminar. A partir de estas tres capas se originarán todos los tejidos, órganos y sistemas del organismo y parte de los tejidos extraembrionarios, con la consiguiente pérdida de capacidad de multiplicarse según avanza su especialización.

Es aquí donde entra la ciencia al descubrir que en los procesos de fecundación invitro, una vez que se ha formado el blastocisto, que implantado en el útero de la madre llevaría a realizar el embarazo, se pueden arrancar las células que hay en su interior, convirtiendo estas en sustitutas de aquellas que murieran por causa de una enfermedad, aunque esto provocara la destrucción del embrión. Estas células que provienen de la masa celular interna del blastocisto tienen el potencial de contribuir a cualquiera de los linajes en función de la posición que ocupan, por lo que se denominarán totipotentes. Por ello extraídas del blastocisto del embrión, se constituyen en células madre embrionarias, que pueden crecer y posteriormente diferenciarse hacia cualquier tejido orgánico.

\section{b) La clonación}

Los avances anunciados han creado en la comunidad científica una urgencia por comenzar a investigar con estas células madre con un futuro tan prometedor. El problema es la obtención de estas células, que exige la existencia de un embrión y el peligro de rechazo, al ser células que provienen de embriones, ajenas al propio organismo. Como solución a estos problemas han surgido, en un breve espacio de tiempo, los defensores acérrimos de la clonación, que proponen producir embriones humanos clónicos de individuos, con los que se evitaría el problema de la obtención y el posible rechazo.

Si nos remitiéramos al punto de vista científico podríamos decir que la clonación es la "producción artificial de células". Desde el punto de vista

7 Esteban Santiago, "Suposiciones y realidades", Nueva Revista, noviembrediciembre, 2002. 
de los fines con los que se realice la clonación se puede distinguir entre clonación reproductiva y clonación terapéutica, siendo la primera la que se realiza con el fin de crear un nuevo ser humano y la segunda la que se limita a producir células a partir de embriones para después diseccionarios, extrayendo de ellos células madre como materia prima para el autotrasplante, con el fin de ayudar a la curación de enfermedades.

\section{c) Células madre adultas}

Junto a estas células embrionarias totipotentes han aparecido, de modo sorpresivo para los propios investigadores, algunas células multipotentes o parcialmente diferenciadas en tejidos de organismos adultos, con capacidad de multiplicación y diferenciación ulteriores. Células que el organismo reserva, capaces de incorporarse al proceso de diferenciación y realizar así la función de reparación de lesiones o regeneración de tejidos. Células que mantendrán a lo largo de la vida la potencialidad de dar lugar a cualquiera de los tipos celulares (células pluripotentes), a algunos tipos (multipotentes) o a uno sólo (progenitoras) ${ }^{8}$ y que uen ocasiones pueden tener mayor potencial de diferenciación que algunas células madre embrionarias» ${ }^{9}$. Estas células se obtendrían de un sujeto adulto, y hoy se conoce su presencia en médula ósea, sangre periférica, sangre del cordón umbilical, cerebro, médula espinal, pulpa dentaria, $v$ asos sanguíneos, músculo esquelético, epitelio de la piel y tejido conjuntivo, córnea, retina, hígado y los conductos del páncreas.

En el fondo, la ciencia cada vez insiste más en afirmar que "la función y el futuro de cada célula depende por una parte de las condiciones en las que se encuentra el genoma y el medio intracelular; y por otra de las interacciones entre las células y las de cada una con los componentes del medio extracelular (el nicho). Por ello al extraerse del organismo, cada tipo celular puede ser reprogramado hacia un linaje diferente del que hubiera seguido de continuar formando parte del organismo del que procede ${ }^{10}$. Fuera de su contexto natural, cada célula queda a merced de la información del medio en que se sitúe, aunque su respuesta seguirá

${ }^{8}$ En Nature, en el mes de julio 2002, Verfaille valida todas y cada una de las premisas necesarias para considerar a una célula madre adulta como pluripotente.

9 Esteban Santiago, "Suposiciones y realidades", Nueva Revista, noviembrediciembre, 2002.

10 Esteban Santiago, "Suposiciones y realidades", Nueva Revista, noviembrediciembre, 2002. 
dependiendo de la información acumulada desde el comienzo de su existencia.

\section{d) La medicina regenerativa}

Por eso apoyadas en estas realidades, en los últimos tiempos han surguido con fuerza las investigaciones de terapia celular o regenerativa, que a través de la manipulación de las células, embrionarias o adultas, pueden cambiar su trayectoria natural y utilizarlas en sustitución de las que sucumbieron por causa de una enfermedad, reparando en el propio organismo lesiones que de otra forma serían irreparables.

Recapitulando este primer punto, podemos resumir el estado actual de la cuestión científica partiendo de las distinción entre las células embrionarias y las células adultas. Las primeras serán aquellas que se extraen de un embrión, $y$ que desde el punto de vista científico tienen la virtualidad de ser totipotenciales, pueden llegar a convertirse en cualquier tipo de órgano. Frente a estas las células madre procedentes de tejido adulto, que tienen capacidad de convertirse en un gran número de órganos (pluripotenciales). En los últimos años los avances científicos en la investigación con seres humanos se han obtenido fundamentalmente con las células madre adultas, que a pesar de su inferior capacidad, presentan menos problemas de rechazo.

A pesar de esto, y con una confianza ciega en su posibilidades, son muchos los que han planteado la posibilidad de utilizar las células embrionarias para la investigación, primero a través de la utilización de los, llamados, «embriones sobrantes" de los procesos de fecundación in vitro y después por medio, incluso, de la clonación de embriones con el objeto de utilizar las células para la investigación. Estas pretensiones requieren un planteamiento jurídico de esta nueva realidad.

\section{EL BIEN JURÍDICO PROTEGIDO: ¿UN ESTATUTO PARA EL EMBRIÓN?}

El embrión se plantea como el objeto jurídico sobre el que debe girar el debate y la reflexión, de su condición derivará el tratamiento, la protección jurídica, de ahí la importancia de delimitarla a través de un Estatuto. Los científicos coinciden en reconocer que a partir de la fecundación existe vida humana y esa vida humana tiene continuidad desde ese momento hasta su muerte natural. A nadie se le escapa que no es lo mismo el 
embrión de una semana que el ser humano adulto, "pero el que no sea lo mismo no quiere decir que no sea el mismo..., el valor del ser humano no está condicionado por la adquisición de determinados atributos. Parafraseando a Musil, yo diría que a quien hay que defender es al hombre sin atributos»" ${ }^{11}$.

Desde el punto de vista legislativo desde 1984 existe un elemento que ha resultado determinante a la hora de establecer el estatuto del embrión: el Informe Warnock. Este documento establece una línea divisoria sustancial en la protección debida al embrión, sancionando que hasta el día 14 después de la concepción el embrión no sería acreedor a una verdadera protección. Desde ese momento se introdujo en la discusión un nuevo concepto, que no se había utilizado nunca hasta ese momento, el de preembrión, de dudoso rigor científico.

A favor de esta distinción se manejan argumentos como la posibilidad de producirse una gemelación, la posibilidad de que el embrión no se constituya como tal sino como una mola hidatidiforme, las tasas de mortalidad existentes en las primeras fases del desarrollo embrionario o la aparición de la estría primitiva, la primera señal del sistema nervioso. Argumentos todos de tinte utilitarista, que inciden no en la existencia de un individuo de la especie humana, sino en la capacidad de sentir placer o dolor.

De hecho, actualmente ese concepto ha vuelto a desaparecer de los manuales de embriología, al no existir solución de continuidad entre el embrión antes y después de su implantación en el útero, pese a lo cual algunas legislaciones como la española, conservan esta distinción, que hoy carece de sustento científico.

Vemos como el asunto se convierte así en un derecho directamente derivado del derecho a la vida, y en el análisis de hasta que punto este pudiera ser aplicable al embrión. Sin necesidad de adentrarnos en un debate tan rico y complicado, para lo que remitimos a publicaciones como los artículos de Miguel Ángel Alegre, ${ }^{12}$ y Oscar Ignacio Mateos y de Cabo $^{13}$, vamos a tratar de establecer, con arreglo a la jurisprudencia de nuestroTribunal Constitucional, la relación entre la investigación con células embrionarias y el derecho a la vida y las consecuencias de esto.

11 Conversaciones con Jesús Ballesteros, NR 72. Noviembre-diciembre 2000

12 Alegre, Miguel Angel. Apuntes sobre el derecho a la vida en España:Constitución, jurisprudencia y Realidad. Revista de Derecho Políticos, $n .^{\circ} 53$, 2002.

13 MATEOS Y DE CABO, Oscar Ignacio. Los límites del derecho a la vida: el problema del tipo de fuente normativa de su regulación. 
Si nos preguntamos por la correcta interpretación del artículo 15 de la Constitución, no hay duda que tendremos que estar a las sentencias constitucionales sobre la materia, que tratan de mantener la coherencia de la sentencia 53/1985 que fundamenta las siguientes posiciones:

1. No existe titularidad de derecho subjetivo a la vida propiamente dicho antes del nacimiento.

2. Esto no impide que en la vida prenatal no esté presente un bien vida humana que debe protegerse por el ordenamiento, como parte de la normativa constitucional.

Esto implica una doble obligación del Estado respecto a la vida prenatal, la de abstenerse de interrumpir u obstaculizar el proceso natural de gestación y la de establecer un sistema legal para la defensa de la vida que suponga una protección efectiva de la misma.

Es claro por tanto que el bien jurídico vida debe protegerse desde que hay vida humana, no necesariamente personal, $y$ que frente a este bien no pueden manejarse criterios de mera utilidad. Como advierte el profesor Serrano Ruiz Calderón "de aceptarse los criterios de utilidad el juego del artículo 15 en relación con la vida prenatal perdería toda virtualidad frente a lo indicado por el Tribunal Constitucional».

¿Y qué es el bien vida? La vida se define como un devenir desde la fecundación y en esta línea, el tribunal entiende que caben diversos niveles de protección. Lo que no cabría entonces es una etapa absolutamente desprotegida, que es lo que se pretende con el preembrión, que se convertiría en un elemento de consumo.Es evidente que la sentencia 116/1999 entiende que la protección dada al embrión no transferido (preembrión) es inferior a la del embrión implantado, algo que sin dejar de ser discutible, desde el momento que asume una denominación que se está abandonando en la terminología científica y que no acogen las legislaciones de los países de nuestro entorno, afirma que la etapa del preembrión no puede estar exenta de protección jurídica, y que todas las acciones que se justifican en esta línea deben hacer relación a la reproducción humana para garantizar su constitucionalidad.

Así se puede observar en la sentencia que argumenta la constitucionalidad de la congelación de preembriones «como el único remedio para mejor utilizar los preembriones ya existentes y evitar fecundaciones innecesarias", o al aclarar que el artículo 12.1 de la ley recurrida establece garantías suficientes para el preembrión al permitir la investigación sobre preembriones viables unicamente con fines de diagnóstico o preventivos para la salud del mismo preembrión. Estableciendo como no viables aquellos «incapaces de desarrollarse para dar lugar a un ser humano». 


\section{EL MARCO LEGISLATIVO: CLONACIÓNY FECUNDACIÓN IN VITRO.}

Como hemos visto en el planteamiento inicial, la determinación del momento en el que comienza la vida, o en la que esta es objeto de protección jurídica y si caben distintos niveles de protección en función del desarrollo de la vida, constituyen las bases del problema jurídico que ha inundado el debate público en los últimos meses.

Nosotros partimos del principio según el cual «por elevados que sean los objetivos de la investigación médica no pueden determinar el momento a partir del cual debe protegerse la vida humana» ${ }^{14}$, un principio que como hemos visto en el punto anterior viene a garantizar nuestra Constitución y que es recogido, en otros ordenamientos como el alemán que protege la dignidad de la persona humana desde el momento de la fecundación del óvulo.

En España la legislación vigente se mueve en el marco del artículo 15 de la constitución que garantiza el derecho de todos a la vida, un derecho que en nuestra norma fundamental, como apunta Alegre, "gira en trono a las nociones, también constitucionales, de dignidad y personalidad, con las que se encuentra inseparablemente relacionado" ${ }^{15}$. El desarrollo legislativo de este derecho en lo que afecta a la investigación con células madre lo encontramos en la Ley 35/1988 sobre Técnicas de Reproducción Asistida y la ley 42/1988 de donación y utilización de embriones y fetos humanos o de sus células, tejidos $u$ órganos. En estas normas que establecen el marco de la regulación de las técnicas de producción de embriones con el fin de facilitar la procreación a aquellas parejas que por diversos motivos deban recurrir a estas técnicas, se establece la prohibición de producir embriones con otro fin que no sea el de implantarlos en el seno de una mujer en un plazo de cinco años y la prohibición de todo tipo de investigación con los embriones viables, pero la norma cae en lagunas jurídicas sorprendentes, al no establecer el destino de los embriones una vez transcurridos cinco años o al no precisar el concepto de viabilidad.

Lo que resulta evidente es que entre las posibilidades de obtención de células madre, a las que nos referíamos anteriormente, las únicas que plantean problemas jurídicos, así como problemas éticos, son la clonación (creación de embriones para la investigación) y la obtención de células de embriones sobrantes de los procesos de fecundación in vitro.

${ }^{14} \mathrm{RAU}$, Johannes. "¿lrá todo bien? Por un progreso a escala humana». Traducción de Ernesto Calabuig, Nueva Revista 76, Julio-Agosto 2001.

15 Alegre, Miguel Angel. Apuntes sobre el derecho a la vida en España: Constitución, jurisprudencia y Realidad. Revista de Derecho Políticos, n. ${ }^{\circ} 53,2002$. 


\subsection{La clonación. La creación de embriones para la investigación.}

Hasta hace poco tiempo la creación de embriones para la investigación era una práctica prohibida por la práctica totalidad de los ordenamientos. Recientemente países como Inglaterra, han aprobado la creación de embriones humanos para investigar y obtener de ellos células madre.

En nuestro país la ley 35/1988 declara en su artículo 3 como "principio general" que "se prohibe la fecundación de óvulos humanos con cualquier fin distinto a la procreación humana", para tipificar esta como infracción administrativa muy grave (20.2B).

En el ámbito de lo penal, el artículo 161 del Código Penal establece las penas asignables a esta misma infracción, que se tipifica como delito. Según este se castiga la creación de seres humanos por clonación y por cualquier otro medio que implique la selección de raza. De la literalidad del artículo "XXX", se desprende la sanción de la clonación reproductiva se ha planteado la duda sobre si la sanción afectaría también a la clonación terapéutica, algo que en nuestra opinión es claro al basarse ambas en el mismo procedimiento, distinguiéndose solamente en el fin que dan al resultado, un preembrión, y por tanto un ser humano.

Podríamos decir que hoy, es un hecho que la clonación está prohibida por nuestro ordenamiento. Aunque, sobre todo tras los últimos anuncios de un grupo de investigadores coreanos que habrían conseguido clonar células humanas, ha tomado fuerza la idea de que es necesario, con o sin reforma del Código Penal, autorizar la clonación terapéutica, lo que sin duda supondría reducir la protección de la vida prenatal, bien jurídico protegido por nuestra constitución.

\subsection{Embriones «sobrantes» de los procesos de fecundación in vitro.}

Ante la prohibición existente en nuestro país de crear embriones para la investigación, los científicos han encontrado en los procesos de Fecundación in vitro, y en las lagunas de la ley 35/1988, una fuente de materia prima para su investigación.

La ley de Fecundación in vitro, 35/1988, establecía la posibilidad de crear embriones con el objeto de implantarlos en el seno materno. Junto a esta disposición, y con el fin de evitar complicaciones innecesarias en caso de que fallará la anidación de estos embriones, permitía la posibilidad de crear más embriones de los que se iban a implantar, procediendo a su congelación hasta el momento que fueran necesarios. 
Independientemente de la opinión que se mantenga sobre el asunto, el principal error de esta legislación era no da respuesta a un problema tanı grave como el de qué hacer con los embriones "sobrantes", aquellos que: finalmente no fueran necesarios en el proceso de la fecundación in vitro, problema que la ley evitó siquiera mencionar.

Pese a esta laguna, la ley era clara al establecer el destino puramente reproductivo de los embriones y en el artículo 13.2, la ley 35/1988 establecía que «toda intervención sobre el embrión o sobre el feto en el útero vivos, o sobre el feto fuera del útero, si es viable, no tendrá otra finalidad terapéutica que no sea la que propicie su bienestar y favorezca su desarrollon. Es decir, la ley de Técnicas de Reproducción Humana Asistida utiliza el término "terapéutica" refiriéndose al bienestar y el desarrollo del propio embrión, no de un tercero.

De esta forma y siempre según la STC 116/1999 (FJ 9.B), la ley 35/1988 garantizaba «la protección jurídica que, constitucionalmente, se garantiza a los nasciturii. Dicha protección del concebido y no nacido es, como hemos visto, consecuencia directa del artículo 15 de la Constitución Española, como declara la STC 53/1985 (FJ 5).

La ley hacía extensiva esta protección también a los preembriones y en su artículo 15, establecía que "solo se autorizará la investigación en preembriones con otros fines que no sean de comprobación de su viabilidad o diagnósticos: a) Si se trata de preembriones no viables. b) Si se demuestra científicamente que no puede realizarse en el modelo animal"), entendiéndose que ambas condiciones, además de una tercera y una cuarta, deben darse al mismo tiempo para poder considerar la experimentación como autorizada.

En concreto, la sentencia del Tribunal Constitucional (STC 116/1999) definía la "no viabilidad»: "no viable hace referencia concretamente a su incapacidad para desarrollarse hasta dar lugar a un ser humano...son así, por definición, embriones o fetos humanos abortados en el sentido más profundo de la expresión".

A pesar de eso, y como resultado de esta ley, eran habituales en España los procesos denominados eufemísticamente de «reducción selectiva de embriones" para evitar embarazos múltiples provocados por la implantación de un número excesivo de embriones, así como la acumulación de embriones congelados, que como hemos visto, se fecundaban a la espera de fallos en el proceso que obligaran a la implantación de nuevos embriones sin necesidad de volver a repetir el proceso de extracción de óvulos y su fecundación.

Estos problemas, que la ley venía arrastrando desde 1988 hacía necesaria una reforma legislativa. Además como consecuencia del crecimiento 
de la medicina regenerativa surge en nuestro país una corriente de opinión, liderada por el científico Bernat Soria que constata las dificultades que la ley $35 / 88$ establecía para la investigación y exige una reforma legislativa que permitiera la investigación con embriones en nuestro país.

Los principios básicos de la reforma deberían venir marcados por la propia ley $35 / 1988$, de 22 de Noviembre, sobre técnicas de reproducción asistida, que explica en su introducción: «...la investigación científica...no debe ser limitada si no es en base a criterios fundados y razonables que eviten su colisión con los derechos humanos y con la dignidad de los individuos y las sociedades que constituyen, a la que no puede renunciarse...conscientes ambas, ciencia y sociedad de que en estricto beneficio del ser humano no siempre va a ser posible ni debe hacerse lo que se pueda hacer. Trátase de asuntos de enorme responsabilidad, que no pueden recaer ni dejarse a la libre decisión de los científicos, que por otra parte tal vez rechazarian."

Desde esta perspectiva el planteamiento originario sería el de comparar el bien jurídico a proteger, el embrión humano, con el resto de los bienes jurídicos que derivarian de su destrucción para ver hasta que punto la contraposición de bienes jurídicos justificaría la investigación.

Los beneficios que podrían aportar las células madre embrionarias hoy no pasan de incógnita, si bien es cierto que se ha experimentado con éxito con células de ratones, aun no se han obtenido resultados positivos con células humanas más proclives al rechazo, aunque se lleve más de diez años experimentando con ellas. Los obstáculos científicos pasarían por el rechazo, ya citado, que obligaría a proteger al paciente, durante toda su vida, con un tratamiento inmunosupresor con todos los riesgos de infecciones y tumores por sus bajas defensas inmunitarias; las posibilidades de formación de tumores, dado la potencialidad de crecimiento de estas células, que exigiría tener capacidad para identificar y eliminar cualquier célula madre con capacidad tumoral, algo que aun no es posible; por último, y al proceder las células madres de procesos de fecundación invitro, como efecto de la manipulación se podia presentar el riesgo de malformaciones $y$ otras alteraciones.

Un criterio básico para plantear la reforma debería ser, "la siguiente norma: si tenemos dudas fundadas acerca de si es lícito o no hacer algo técnicamente factible, debe quedar prohibido en tanto no se hayan disipado todas las dudas fundadas. Conozco la frase "los demás también lo hacen", pero, de entrada, a nuestros propios hijos siempre les decimos que tienen que hacer lo que está bien, sin importar lo que hagan los demás. Y tampoco aceptamos este argumento al hablar del trabajo infantil, la esclavitud o la pena de muerte. Lo mismo vale para otro argumento similar: «Si no lo 
hacemos nosotros acabarán haciéndolo otros". Este argumento refleja una: capitulación ética. Eso sí, parece especialmente plausible cuando se le da. una connotación económica: si no hacemos tal o cual cosa lo harán otros y se colocarán a la vanguardia del progreso, gozarán las ventajas comparativas, nos expulsarán del mercado- $»^{16}$.

Desde esta perspectiva habría que considerar también alternativas: para lograr el mismo fin que persigue la investigación con células madre: embrionarias, así observamos como cada vez se presenta con más fuerza! la potencialidad de las células madre adultas, cuya pluripotencialidad es: hoy un hecho, con capacidad de diferenciación en vivo, y sin el riesgo de: la aparición de tumores. Lo que presenta nuevas posibilidades de terapia। celular con resultados demostrados ${ }^{17}$. Así, y siempre desde la perspectiva। legislativa podemos afirmar que las células madre embrionarias, procedentes de los embriones crioconservados sobrantes de la práctica de la fecundación in vitro, no son necesarias para las terapias regenerativas, por lo que en ningún caso se podría justificar el ataque al embrión, bien jurídico digno de protección, según la doctrina de nuestro TC y la legislación vigente en nuestro país.

\section{LA REFORMA DE LA LEY $35 / 1988$ Y LA LEY AUTONÓMICA ANDALUZA}

A finales del año 2002, el Ministerio de Sanidad decidió proceder a la reforma de la citada ley 35/88. El punto clave de la nueva legislación, en consonancia con las legislaciones avanzadas, debería ser el de suprimir el problema desde su raíz, evitando la creación de embriones sobrantes, para lo que la ley debería restringir el número de embriones a fecundar para su implantación a los estrictamente necesarios para la viabilidad del proceso, (las legislaciones alemanas e italianas, establecen el número de tres). Así se evitaría el problema desde el principio evitando cualquier tipo de tentación de utilizar el material celular como material de investigación, convirtiéndolo en mera mercancía.

Con esta decisión se solucionarían los dos grandes problemas de la ley $35 / 1988$, el de los partos múltiples que se venían produciendo repetida-

${ }^{16}$ RaU, Johannes. "¿lrá todo bien? Por un progreso a escala humana». Traducción de Ernesto Calabuig, Nueva Revista 76, Julio-Agosto 2001.

17 Navarra, Valladolid... hoy es un hecho que las células madre de tejidos adultos pueden inyectarse en distintos órganos como el corazón, músculos, hígado, pulmón o instentino, transformandose in situ en células de estos tejidos. 
mente, y que provocaba la "reducción embrionaria", sistema por el que se eliminaban los embriones con peor aspecto antes de la implantación, y que la reforma prohibe; y la creación de embriones congelados que, ante la imposibilidad de dar solución alguna, se iban acumulando en las neveras de los Centros de Reproducción asistida, condenados por la propia ley a morir transcurridos cinco años o a permanecer eternamente congelados, mientras iban sufriendo un lento proceso de degeneración. Ante este problema creado, el de un numero indeterminado de embriones congelados (entre $30 \mathrm{y}$ 300 mil), la reforma de la ley también debería ofrecer una solución.

La reforma provee una solución adecuada para evitar la acumulación de blastocitos congelados. A partir de ahora solamente se podrán fecundar e implantar un máximo de 3 óvulos en cada ciclo, por lo que además se reducirá el riesgo de embarazos múltiples. Solamente se congelarán embriones en casos excepcionales, en los que no sea posible provocar otra ovulación posterior a la mujer. Sin embargo, esta situación se desincentivará mediante obligaciones tales como la contratación de un seguro durante todo el periodo en que el embrión esté crioconservado, que puede durar durante el resto de la vida fértil de la mujer. Además, no será posible utilizar estos embriones con fines distintos a la reproducción.

Tras prohibir la reducción embrionaria, sistema por el que se eliminaban los embriones con peor aspecto antes de la implantación, la reforma aborda el problema de los embriones congelados existentes en el momento de su aprobación. La solución propuesta es permitir a los progenitores decidir si quieren implantarse dichos blastocitos, si quieren darlos en adopción o si, por el contrario, desean dejarlos morir. Los embriones para los que no pueda localizarse a sus padres, se mantendrán congelados durante cuatro años en espera de la difícil posibilidad de la adopción. Después de este tiempo, se les dejará morir y se utilizará su material biológico para investigación para paliar enfermedades e intentar salvar otras vidas en un único centro controlado por el Estado, siendo éste tratado en base a los protocolos de donación de órganos, impidiendo así la posibilidad de lucro con los mismos. Esto ocurrirá solamente con los embriones congelados hasta ahora, fruto de los mecanismos regulados por la ley de 1988. A partir de la entrada en vigor de la nueva ley, ningún embrión humano recientemente concebido podrá ser utilizado para un fin distinto a la procreación.

La reforma de la Ley consta de un artículo único, por el cual se reforman los artículos cuarto y once de la Ley 35/1,988 de 22 de noviembre sobre Técnicas de Reproducción Asistida, al cual se añade una disposición adicional única y cuatro disposiciones finales. Sólo se examinarán los preceptos que puedan presentar una redacción conflictiva desde el planteamiento que aqui se mantiene. 
El texto, tras una presentación larga y minuciosa en la que trata de dar respuesta a todos, contentando a unos y otros, modifica dos artículos de la Ley sobre Técnicas de Reproducción Asistida (35/1988) que -en esto todos coinciden - se ha mostrado anticuada e ineficaz.

Pronto se cae en el primer error al volver a utilizar el término preembrión, un concepto que pretende «sugerir que en los catorce días posteriores a la fecundación no existiria todavía más que una realidad prehumana que no merecería el respeto debido a los seres humanos. Pero esta ficción lingüística oculta el hecho de la continuidad fundamental que se da en las diversas fases del desarrollo del nuevo cuerpo humano. Donde hay un cuerpo humano vivo, aunque sea incipiente, hay persona humana $y$, por tanto, dignidad humana inviolable».

El aspecto más importante es la modificación del artículo 4, en el que se establece la regla general según la cual se podrán fecundar un máximo de tres embriones en cada ciclo que se deberian transferir en su totalidad, hasta aquí nadie, salvo las clínicas de reproducción asistida que ven peligrar su negocio, había puesto pegas, ya que la solución resuelve problemas como la reducción embrionaria y la congelación de embriones:

1. Con carácter previo al inicio del tratamiento, el equipo médico analizará la situación de cada mujer o de cada pareja, con objeto de que, teniendo en cuenta su proyecto reproductivo $y$ de acuerdo con lo establecido en los apartados 2 y 3 de este artículo y en el apartado $3 \mathrm{del}$ artículo 11, pueda ajustar aquellos aspectos del tratamiento relacionados con la intensidad de la estimulación ovárica, el número de ovocitos que se pretende fecundar $y$ el número de embriones que se pretende transferir. Para ello se tendrá en cuenta las circunstancias particulares de la mujer, tales como su edad, su historial clínico o las posibles causas de esterilidad En todo caso el tratamiento deberá evitar la gestación múltiple, la práctica de la reducción embrionaria y la generación de preembriones supernumerarios.

2. Sólo se autoriza la transferencia de un máximo de tres prèembriones en una mujer en cada ciclo.

El conflicto se produce con las excepciones a esta regla general; tras una versión ínicial en el que el anteproyecto de ley establecía un criterio restrictivo según el cual, «3.- Se fecundará un máximo de tres ovocitos para que sean transferidos a una mujer en el mismo ciclo. Excepcionalmente, cuando tras sucesivos fracasos para alcanzar la gestación, existan dificultades adicionales que reduzcan la probabilidad de anidación y gestación, constatadas por la evidencia científica, se podrá fecun- 
dar un número superior de ovocitos, siempre que sea asumible por la pareja dentro de su proyecto reproductivo. En estos casos se estará a lo previsto en el apartado tres del art. 11 de esta Ley", lo sorprendente fue ver cómo, tras presentar esta redacción a los medios y a las partes interesadas. el Ministerio, bajo la presión de las clínicas, decidió modificar la redacción, que quedó como sigue: «3. Se fecundará un máximo de tres ovocitos que puedan ser transferidos a la mujer en el mismo ciclo, salvo en los casos en los que lo impida la patología de base de los progenitores. Las tipologías fisiopatológicas de estos casos en los que se permita fecundar un número mayor de ovocitos, siempre que sea asumible por la pareja dentro de su proyecto reproductivo, serán especificados en un protocolo elaborado por el Ministerio de Sanidad y Consumo con el asesoramiento e informe previo de la Comisión Nacional de Reproducción Humana Asistida." Esta modificación de última hora ha introducido en el proyecto una dosis de incertidumbre, al moverse en la ambigüedad más absoluta, y dejar un tema tan decisivo para el futuro de la ley, en manos de un protocolo de contenido incierto. Al establecer el desarrollo reglamentario de un asunto tan peliagudo, las posibilidades de ir incluyendo fisiopatologias como la edad, anulando la exigencia de fracasos sucesivos, y no estableciendo ningún tipo de control, pone todo en manos de los médicos que por mera comodidad no dudarán en "asegurar", preparando embriones de "recambio". De lo que no hay duda es de que al amparo de esta excepción se volverán a producir preembriones supernumerarios, embriones que muchos denominan sin pudor sobrantes, y será necesario proceder a su congelación. Algo que ha confirmado la reciente aprobación del Protocolo de excepciones.

Los problemas aumentan al plantearnos el destino de estos preembriones, a los que habría que dar una solución, la ley establece en el artículo 11.3 que "serán crioconservados por un plazo equivalente a la vida fértil de la mujer con el objeto de que se le puedan transferir en intentos posteriores". Estableciendo la obligación de los progenitores de firmar un "Compromiso de Responsabilidad sobre sus Preembriones Crioconservados", en el que se incluirá una cláusula por la que la pareja o la mujer, en su caso, otorgarán su consentimiento para que, en el caso de que los preembriones crioconservados no les fueran transferidos en el plazo previsto, sean donados con fines reproductivos como única alternativa».

Además el artículo 11.5 establece como garantía para estos embriones crioconservados la obligación de que uantes de iniciar un tratamiento de reproducción asistida será necesario comprobar que la pareja o la mujer, en su caso, no tengan preembriones crioconservados en algún centro nacional de reproducción asistida. En el caso de que se comprobará su existencia y siempre que no concurra alguno de los impedimentos previs- 
tos en esta Ley para disponer de ellos, no se podrá iniciar un nuevo tratamiento".

Así, como acabamos de ver la ley establece una doble solución, la implantación en la mujer, cuyos óvulos fueron fecundados dando lugar a aquellos embriones, o su donación con fines reproductivos. La solución que podría parecer aceptable, presenta aspectos oscuros, pues no resuelve qué se ha de hacer con esos embriones transcurrido el periodo fértil de la mujer, si ni ésta deseó una nueva implantación de los mismos, ni ninguna otra mujer ha deseado solicitar su donación. Nada dice la ley ante la posibilidad, nada remota, de que no se produzca ninguna de estas opciones. Dejando a estos en un "limbo legislativo", como denuncia Jaime Lissatveski, Portavoz del Grupo Socialista en la Comisión de Ciencia y Tecnología; por su parte el Profesor Romeo Casabona advierte: "se ha excluido el uso de estos embriones para la investigación y su misma descongelación, ¿qué habrá que hacer con ellos entonces, pues «legalmente» no existirán embriones sobrantes nuevos?" ${ }^{18}$

Así observamos como algunas medidas que suponían avances en el buen camino, como la limitación del número fecundaciones y la exclusión expresa de la utilización de estos embriones con otro fin distinto que el de la reproducción, quedan convertidas en papel mojado de imposible aplicación. El peligro de que la situación final termine siendo la misma que en la actualidad, cuando se habla de entre 30.000 y 200.000 embriones congelados, es evidente, $y$ ante el vacío legal no parece muy aventurado anticipar que haya que recurrir a la solución que establece la reforma de la Ley en la disposición final primera.

El vacio legislativo ya comentado no nos deja otra opción que acudir a la Disposición final primera que regula el destino que se ha de dar a los embriones crioconservados con anterioridad a la entrada en vigor de la Ley, estableciendo para ello cuatro opciones: $1^{\mathrm{a}}$.- el mantenimiento de la crioconservación hasta que sean transferidos de acuerdo con lo establecido por la Ley 35/1.988 de 22 de noviembre sobre Técnicas de Reproducción Asistida; $2^{a}$.-la donación, sin ánimo de lucro, con fines reproductivos a otras parejas que estén en lista de espera de Fecundación in Vitro, según lo previsto en los arts. 5, 7, 8 y 9 de la Ley $35 / 1.988 ; 3^{\mathrm{a}}$.- el consentimiento para que las estructuras biológicas obtenidas en el momento de la descongelación puedan ser utilizadas con fines de investigación, dentro de los límites previstos en la presente dis-

${ }^{18}$ Romeo Casabona, Ante la reforma de la ley sobra técnicas de reproducción asistida. ABC, 9.8.2003. 
posición final, no permitiendo en ningún caso la reanimación; o $4^{a}$.- proceder a la descongelación sin otros fines.

Las dos primeras opciones se mueven dentro de los propios criterios establecidos por el artículo 11 de la Ley, valgan pues las objeciones allí planteadas. La tercera opción es atentatoria gravemente contra la dignidad humana del embrión. Se ha dicho en varias ocasiones que el embrión es un ser humano, por lo que en ningún caso ni bajo concepto alguno puede ser objeto de investigación científica ni de manipulación de tipo alguno, pues es reducir el embrión a cosa, a "material genético", idea que repugna a su dignidad. Por último la opción parece indicar que se deja en poder de la pareja progenitora o de la mujer la posibilidad de descongelar el embrión para dejarlo morir, aunque esto último no lo afirma, pero no parece que pueda ser otra la conclusión. En cualquiera de los casos, se deja a la potestad de los progenitores el destino del embrión, con lo que se está considerando que aquellos tienen derecho sobre el hijo a decidir sobre su dignidad y sobre su vida, lo que presenta graves dudas éticas, por no decir un rechazo ético.

El vacío legislativo ordinario nunca podría cubrirse con esta disposición adicional, aplicable sólo a los embriones anteriores a la aprobación de la ley (23.XI.2003). Por eso pensamos que si el legislador quiere de verdad solucionar el problema debería eliminar cualquier tipo de excepción, prohibiendo la congelación de embriones humanos. Esta solución no supondría coste alguno para las mujeres que se someten a estas técnicas, que siempre podrían recurrir a la congelación de óvulos, técnica que ya ha producido resultados favorables, no supone la congelación de embriones Y que la propia ley admite en su artículo 11.2: "Se autoriza la crioconservación de óvulos con fines de reproducción asistida, dentro de experiencias controladas en los términos reglamentariamente establecidos. A partir del momento en el que exista evidencia científica de la seguridad y eficacia de estas técnicas de crioconservación, el Ministerio de Sanidad y Consumo podrá autorizar el uso generalizado de las mismas, si se considerara adecuado tras la evaluación correspondiente de dichas experiencias controladas". Algunos alertan sobre los peligros que podrían presentar estas técnicas, como si los óvulos congelados fueran merecedores de mayor protección que los embriones; y es que cuando se intenta hacer política para contentar a todos, primero se olvidan las razones y después se deja de hacer política.

Además se modifican, los apartados 1 del artículo 11 de la Ley 35/1988 de 22 de noviembre sobre Técnicas de Reproducción Asistida:

Artículo 11.- 1.- El semen podrá crioconservarse en Bancos de gametos autorizados durante un tiempo máximo de veinte años. Este límite podrá ser 
ampliado cuando el desarrollo de las técnicas confirme la posibilidad de prolongar su crioconservación sin afectar a la calidad de los gametos.

Por último, se establecen las penalizaciones para los incumplimientos de la ley, añadiendo dos nuevos puntos al artículo 11 que establece:

6. Los centros de Fecundación in Vitro que procedan a la crioconservación de preembriones humanos de acuerdo con lo establecido en este art., deberán disponer de un seguro o instrumento equivalente, que garantice su capacidad para compensar económicamente a las parejas en el supuesto de que se produjera un accidente o siniestro que afecte a los preembriones crioconservados.

7. El incumplimiento de lo establecido en el art. 4 y 11 de esta Ley podrá dar lugar a la suspensión temporal o pérdida de la autorización como centro de reproducción humana asistida.

Esta penalización que establece el párrafo séptimo del precepto comentado parece insuficiente para lograr evitar la generación de embriones crioconservados o el aborto de los que resultaron implantados y no sean deseados. Quizás sería conveniente una reforma del Código Penal que tipificase conductas relacionadas con la fecundación artificial y el tratamiento de embriones, dado que está en juego la dignidad humana y el derecho a la vida.

El párrafo segundo de la disposición final regula el caso de los preembriones existentes en el momento de la aprobación de la ley, que cuenten con el consentimiento expreso de sus progenitores para que sean donados con fines reproductivos a otras parejas que estén en lista de espera de Fecundación in Vitro, respecto de los cuales establece la norma de mantenerlos criconservados durante un plazo de cinco años más, transcurrido el cual sin que se produzca la donación, será cedidos al Centro Nacional de Transplantes y Medicina Regenerativa.

También se establece la posibilidad de mantener crioconservados estos embriones ya existentes durante un plazo de cuatro años, más con el fin de que puedan ser donados con fines reproductivos a otras parejas que estén en lista de espera de Fecundación in Vitro, cuando se desconozca la pareja progenitora o la mujer, en su caso, de los preembriones crioconservados, o cuando no se haya podido recibir el consentimiento informado én el periodo de un año. También, si no se produce la donación efectiva en dicho plazo, serán cedidos al Centro Nacional de Transplantes y Medicina Regenerativa. Parece que no hay duda que el fin de estas cesiones no es otro que el de la descongelación y la posterior obtención de las células, intención que queda patente en el párrafo tercero de esta disposición final, en el que se dice: «3.- Reglamentariamente se determinarán las condiciones 
específicas en las que se podrán utilizar las estructuras biológicas a las que se hace referencia en los apartados anteriores, que en cualquier caso serán tratados de acuerdo con la legislación vigente sobre donación y utilización de células y tejidos de origen humano». Luego la finalidad de esos embriones es su utilización como material genético, destinado a la investigación.

Ese destino del embrión como material genético se vuelve a poner de manifiesto en el apartado cuarto, en el que se dice: "4.- Corresponderá al Centro Nacional de Transplantes y Medicina Regenerativa la aplicación del procedimiento de descongelación de los preembriones cuyas estructuras biológicas vayan a ser utilizadas en el ámbito de la investigación biomédica y la medicina regenerativa, bajo unas normas estrictas de control. En todo caso dichas estructuras biológicas deberán servir para objetivos de investigación de particular importancia, tales como el progreso de la investigación fundamental o la mejora de los conocimientos médicos para la puesta al día de nuevos métodos diagnósticos, preventivos o terapéuticos aplicables al hombre».

En resumen estamos ante un texto legal que permite la descongelación de los embriones congelados existentes en el momento de la aprobación de la ley, y reduce sin terminar de resolver el problema de la acumulación de embriones. Nuestra valoración pasa por denunciar que desde el principio incurre en ambigüedades, como la utilización del término preembrión, y clamorosos vacíos legales como el destino de los embriones sobrantes producidos tras la aprobación de la ley o la reforma de la Comisión Nacional de Reproducción Asistida, por su falta de operatividad, ya que hasta el momento sólo ha elaborado un Informe Anual en 1998, lo que hace necesario plantearse esta figura, para que sea de verdad una institución al servicio del bien común y no de clínicas directamente interesadas económicamente en el asunto. Estas carencias privan al texto de toda eficacia y abren la posibilidad de que a través de las excepciones que se aprobarán por vía reglamentaria todo cambie para seguir igual.

\section{Legislación Autonómica}

El día 8 de octubre de 2003, y con la reforma de la ley 35/1988 en plena tramitación parlamentaria, el Parlamento de Andalucía aprobó una ley que regula la investigación en Andalucía con preembriones humanos, siendo la primera de una serie de Comunidades Autónomas ${ }^{19}$ en afrontar la legislación de una materia, labor para la que no está claro que sean

${ }^{19}$ Además de Andalucía, han anunciado su intención de legislar sobre la materia Asturias, Extremadura, Aragón y Castilla-La Mancha. 
competentes. Estas leyes autonómicas pretenden ser la base jurídica de una serie de convenios de investigación

En su introducción, el texto de la ley establece que "se utilizarán como fuente de células madre los preembriones sobrantes de las técnicas de reproducción asistida que llevan congelados más de cinco años».

Asimismo, dicha introducción explica que "las células madre de origen embrionario...se obtienen de la masa celular interna del blastocito o preembrión entre 5-14 días tras la fecundación del óvulo". Dichas células madre, explica el texto, podrían eventualmente servir para la curación de enfermedades de personas adultas, por lo que el legislador autonómico concluye que esta ley "regula la utilización de los preembriones congelados excedentes de los protocolos de reproducción asistida para la investigación con fines terapéuticos». Esta interpretación de la palabra «terapéutican, que trata de hacer compatible la ley autonómica con la comentada ley $35 / 88$, no hay duda de que se está refiriendo a un tercero, dado que el preembrión es destruido en el proceso de extracción de las células madre. Algo que según hemos visto anteriormente no tendría cabida en el ordenamiento que utiliza el término "terapéutica» refiriéndose al bienestar y el desarrollo del propio embrión, no de un tercero.

En el artículo 1 de la ley andaluza, se afirma que "con fines de mejorar la salud y la vida de las personas, utilizando los preembriones sobrantes de las técnicas de fecundación in vitro, que, a los efectos previstos en el artículo 15.3.a de la Ley 35/1988, de 22 de Noviembre, por la que se regula las técnicas de Reproducción Humana Asistida, se considerarán no viables por haber transcurrido más de cinco años desde su crioconservación". La interpretación que hace la ley autonómica andaluza, en la que se establece que los upreembriones criogenizados durante más de 5 años" son equivalentes a "preembriones no viables» es totalmente arbitraria, no responde a los últimos avances científicos y no cumple en modo alguno con los criterios de la definición de "preembrión no viable» del Tribunal Constitucional, dado que una gran cantidad de los preembriones considerados en Andalucía como no viables por el mero hecho de llevar criogenizados más de 5 años son, en realidad, capaces de desarrollarse en el seno materno y dar lugar a una persona ${ }^{20}$.

${ }^{20}$ Con relación a la realidad científica y respecto a preembriones que han estado criogenizados por un periodo superior a cinco años, es preciso constatar lo siguiente:

- La página web del Instituto de Genética y Fecundación In Vitro (Genetics \& IVF Institute) de Virgina y Maryland, EEUU, en la sección de Congelación de Embriones (Embryo Freezing) explican literalmente que «se han producido embarazos satisfactorios con embriones que llevaban 9 años criogenizados". 
De nuestro ordenamiento jurídico se desprende que el límite de conservación de $\mathbf{5}$ años fue establecido con la intención de que se congelara tan solo un número prudente de preembriones, así como para que los que hubieran sido criogenizados fueran implantados en un plazo que asegurase plenamente su adecuada conservación y viabilidad. En cuanto a los preembriones que a día de hoy han sobrepasado el plazo de conservación dada la dinámica operativa ejercida por las clínicas de reproducción asistida, la única forma legal para determinar la viabilidad o no viabilidad de los mismos, con la técnica disponible, es la descongelación en un proceso de adopción prenatal. Dicho proceso implica la posible implantación del preembrión en una mujer preparada para tal efecto, previa a la cual se analiza el preembrión descongelado para determinar su estado, pero lo que no cabe es decretar su inviabilidad, por el mero paso del tiempo.

Ya hemos visto como la ley $35 / 88$ en su artículo 15 , la ley declara que «solo se autorizará la investigación en preembriones con otros fines que no sean de comprobación de su viabilidad o diagnósticos: a) Si se trata de preembriones no viables. b) Si se demuestra científicamente que no puede realizarse en el modelo animal", entendiéndose que ambas condiciones, además de una tercera y una cuarta, deben darse al mismo tiempo para poder considerar la experimentación como autorizada. Tal interpretación está avalada por la sentencia del Tribunal Constitucional 116/1999, de 17 de junio de 1999, que, como hemos visto, define la «no viabilidad»: «no viable

- El Director del Centro para la Ciencia Reproductiva Aplicada (Center for Applied Reproductive Science, Jonson City, Tennessee) Sam Thatcher, M.D., Ph.D., considerado como autoridad a nivel internacional en la materia, declara en una reciente entrevista publicada en "Panel de expertos en embarazo y paternidad", en StorkNet.com, que "nadie sabe por cuanto tiempo se mantiene la viabilidad de los embriones congelados. Ha habido embarazos satisfactorios después de 10 años. Todos están de acuerdo en que cuanto antes salga del congelador, mejor, pero esto es por otras razones diferentes a la salud del embrión".

- El miércoles 18 de Febrero de 1998, el diario El Mundo, entre otros, publicaba la noticia del nacimiento en perfecto estado de salud de Billy, congelado como preembrión durante siete años y medio, de una mujer norteamericana de 44 años de San Fernando Valley, cerca de Los Angeles. El doctor Michael Vermesh, un especialista en tratamientos de parejas infértiles, explicó los resultados. En el mismo artículo de El Mundo, la Doctora Montserrat Boada, del Instituto Dexeus de Barcelona, aseguró que «no existe un límite para la congelación de un embrión, ya que en buenas condiciones de congelación no tiene por qué deteriorarse. Los límites suelen estar impuestos por las legislaciones". El Mundo concluía explicando que "la comunidad científica internacional lleva tiempo reclamando una ampliación de los plazos de almacenaje de embriones". 
hace referencia concretamente a su incapacidad para desarrollarse hasta dar lugar a un ser humano...son así, por definición, embriones o fetos humanos abortados en el sentido más profundo de la expresión".

En la Disposición Transitoria Primera, el texto dice que "los progenitores de preembriones sobrantes ya existentes a la entrada en vigor de la presente Ley, deberán ser localizados a fin de que manifiesten su voluntad sobre la posibilidad de donación para la investigación".

El carácter transitorio de esta disposición y el principio general que establece que "Para los que «no existan» (se congelen en el futuro), según el artículo tercero de la ley andaluza, se habrá de lograr entonces el pertinente permiso, antes de que los preembriones "existan», es decir, justo antes del proceso de fecundación y congelación. Dice el citado artículo que entonces, "los preembriones que hayan sido donados por los progenitores...serán puestos a disposición del Comité de Investigación con Preembriones Humanos, por los Centros de Reproducción Asistida, una vez transcurrido el plazo de cinco años de crioconservación" vulnerarian el principio general que prohibe "la creación de embriones humanos con fines distintos a la reproducción" que se recoge tanto en la ley 35/88 así como el artículo 161 del Código Penal. Con lo que se estaría abriendo la puerta de forma consciente, de facto y sin ningún género de duda a la fecundación de óvulos con fines distintos a la procreación, con tan solo un retraso de 5 años para su efectiva utilización indebida.

El gobierno instó en su momento correspondiente recurso de inconstitucionalidad contra la ley andaluza, recurso que ha sido admitido a Trámite por el Tribunal Constitucional. Recientemente el nuevo Gobierno ha decidido retirar el recurso. El recurso inicialmente presentado, en nuestra opinión, estaba plenamente justificado ya que la pretensión de la Junta de Andalucía de "dotar de soporte jurídico" al acuerdo adoptado resulta inconstitucional. A pesar de la autoatribución de competencias del Parlamento de Andalucía que en virtud del artículo 13, aptdo. 21 de su Estatuto que le atribuye competencia exclusiva en materia de sanidad e higiene y el aptdo. 29 que dispone que la Comunidad Autónoma de Andalucía tiene competencia exclusiva en investigación, no podemos olvidar que estas competencias exclusivas son atribuidas siempre sin perjuicio de lo que establezca el articulo 149.1 de la Constitución española que en estos puntos es clara al determinar que el "fomento y coordinación de la investigación científica y técnica»(149.1.15), asi como las "bases y coordinación general de la sanidad" (149.1.16) se atribuyen en exclusiva al Estado. Como hemos visto la ley andaluza no desarrolla, sino que modifica y contradice la Ley 35/1988 en materia sanitaria y de investigación, además, de vulnerar la protección otorgada a los embriones no nacidos por el Tribunal Constitucional en sus sentencias 53/1985 y 116/1999. 


\section{UTILIZACIÓN CIENTÍFICA DE LOS EMBRIONES «SOBRANTES», OTRAS ALTERNATIVAS CONFORMES A LA LEGALIDAD.}

Científicamente existe una fórmula que, evitando los problemas jurídicos y éticos que supone la congelación de embriones, permitiría cumplir los fines que esta persigue: la congelación de ovocitos.

Durante las discusiones de la reforma legislativa a la que nos hemos referido a lo largo de este artículo se ha denunciado el peligro que suponía la prohibición de congelar embriones para aquellas madres que quisieran someterse a tratamientos de fecundación in vitro. El motivo era la posibilidad de que ninguno de los embriones implantados, que la ley establece en un máximo de tres, anidaran en el útero; ante el fracaso del tratamiento sería necesario volver a proceder a la extracción de óvulos con la consiguiente incomodidad para la futura madre. Este ha sido el argumento que ha llevado al Gobierno a remitir a un protocolo de excepciones que deberá aprobar el ministerio de Sanidad, la norma general. Este protocolo que aun no ha sido desarrollado, además de plantearnos dudas de constitucionalidad, al dejar en manos del poder ejecutivo un aspecto que determina decisivamente el contenido de la ley, puede convertirse en un cajón de sastre, en el que por la vía de los hechos, y a través de la inclusión de excepciones genéricas, se vacíe de contenido a la reforma, invalidando todos sus logros.

Por eso consideramos conveniente hacer referencia, antes de finalizar el artículo, a otra alternativa conforme a la legalidad, que respondería a las exigencias planteadas, sin necesidad de establecer excepciones a la ley.

En el año 2002 el Ministerio de Sanidad y Consumo aprobó un Real Decreto en el que se autorizan experiencias controladas de utilización de óvulos congelados con fines reproductivos. Esta norma, desarrollo de la ley $35 / 88$ y que no ha sido modificada por la reforma, permite que se puedan realizar fecundaciones in vitro a partir de óvulos criopreservados o congelados, algo que impedia el artículo $\mathbf{1 1 . 2}$ de la ley, que exigia unas garantías de viabilidad tras la descongelación, que no se consideraban garantizadas. Como ha venido recordando la Comisión Nacional de Reproducción Asistida, esta fórmula contribuiría a la disminución de la congelación de embriones sobrantes de las técnicas de reproducción asistida.

La reforma de la ley, no ha aprovechado la oportunidad que le proporcionaba la autorización de fecundación de óvulos congelados, que como hemos comentado podría convertirse en la solución ante posibles fracasos sin necesidad de acudir a la congelación de embriones $y$ ha argumentado que la experiencia aun no es suficiente, como si tratará de conceder mayor protección jurídica al óvulo que al embrión. De todos modos, 
y aunque la reforma que consideró incluir un artículo en este sentido, finalmente renunció a ello, esperamos que los avances científicos hagan recapacitar al legislador estableciendo esta vía como la ordinaria para solucionar posibles fracasos en las prácticas de fecundación in vitro. La protección jurídica del embrión lo merece. 